\title{
Nota Técnica: \\ Yeserías históricas de Morata de Tajuña (Madrid)
}

\author{
Technical Note: \\ Historic gypsum-kilns (Morata de Tajuña, Madrid)
}

$\underline{\text { O. Puche Riart }}^{(*)}$, L. F. Mazadiego Martínez $z^{(*)}$, J. E. Ortiz Menéndez ${ }^{(*)}$ y J. F. Llamas Borrajo(*)

Recepción/Received: 14-VI-06

Aceptación/Accepted: 8-XI-06

RESUMEN

En Morata de Tajuña y pueblos limítrofes hay una importante tradición yesera y calera, así como de otras industrias de materiales de la construcción ya desaparecidas, sobre todo en los años 60-70 del pasado siglo, debido a cambios en los sistemas productivos (paso de sistemas discontinuos a continuos, hornos mayores, etc.) (1). Por eso aún se conservan algunos hornos y también viven antiguos productores, a los que hemos podido preguntar sobre los procesos productivos.

En el marco de un proyecto de investigación de la Consejería de Educación de la Comunidad de Madrid titulado "Arqueología Industrial: conservación del patrimonio minero-metalúrgico madrileño (IV)" se están identificando e inventariando viejas yeserías, recuperando la historia yesera local, reconstruyendo los flujos productivos y entrevistando a antiguos operarios. De esta manera, se pretende evaluar el estado del patrimonio, planteando la conservación de algunos de estos elementos.

Palabras claves: hornos morunos, yeso, cal, cemento, Madrid.
SUMMARY

In the locality of Morata de Tajuña and surroundings there was an important settlement of gypsum pits and limekilns, together with other historical industries, now disappear. These activities were developed mainly during the 1960 's and 70's, but its production decreased because of changes in the productive processes (substitution of discontinuous processes by continuous ones, higher kilns, etc.) (1). Nevertheless, some of these furnaces still remain, as well as ancient workers who have provided important information.

Within the research project funded by the Madrid's Government, entitled: Industrial archaeology: Conservation of the mining and metallurgical heritage of Madrid (IV), ancient gypsum pits have been identified and inventoried. The ancient gypsiferous extraction history was recovered and the productive processes fluxes were reconstructed. The state of the heritage is evaluated and the conservation of some of the elements is recommended. Likewise, the intangible heritage was also investigated, being able to show a legend related with these kilns.

Keywords: moorish kilns, gypsum, lime, cement, Madrid.

(*) Escuela Técnica Superior de Ingenieros de Minas, Universidad Politécnica de Madrid (Madrid, España).

Persona de contacto/Corresponding author: octavio.puche@upm.es 


\section{ANTECEDENTES HISTÓRICOS}

Morata de Tajuña se encuentra situada a 35 kilómetros de la capital, limitando al norte con Arganda del Rey; al sur con Chinchón y Valdelaguna; al este con Perales de Tajuña; y al oeste con San Martín de la Vega. Desde un punto de vista litológico, los materiales que configuran su término municipal son vallesienses y aragonienses (Mioceno) en el norte y sur, esto es, en las partes de mayor cota de Morata. En cambio, los materiales del casco urbano y la vega corresponden al Cuaternario. Las zonas más altas acaban formando una amplia planicie pobre en vegetación, donde las calizas denominadas "del páramo" conforman el nivel de colmatación de esta cuenca lacustre. La erosión fluvial ha puesto al descubierto los niveles subyacentes, tal es el caso de los yesos. Según Martín Bourgón, Campos Juliá y San José Lancha (2) "prácticamente todos los escarpes de yeso están jalonados de canteras con mayor o menor importancia".

Toda vez que los suelos de Morata son calizos y yesíferos, no extraña que los habitantes de esta comarca hayan aprovechado dicha riqueza mineral para obtener cal y yeso a través de hornos artesanales. De hecho, en el siglo XVI, en las Relaciones Topográficas de Felipe II, concretamente en la respuesta no 30 de los representantes de Morata de Tajuña al cuestionario entregado se señala que "las casas y edificios de dicha villa de Morata son de tapias de tierra y yeso..." (3). Esto nos lleva a pensar en un aprovechamiento histórico de los yesos locales, como es lógico de acuerdo al contexto geológico del municipio. En esos mismos años, los términos de Gózquez, Santisteban, Piel, Pajares y Aldehuela eran dehesas, limítrofes con el término de Morata, que se utilizaban como pastizales para el ganado. La explotación se desarrollaba en régimen de arrendamiento temporal de seis a nueve años. Pajares, por ejemplo, fue explotada por el Real Monasterio de El Escorial, al que el rey Felipe II la donó en 1577. Al margen de esta actividad ganadera, se producían yeso y tejas en dichos lugares para luego venderlos en Madrid (4).

En las Respuestas al Catastro del Marqués de la Ensenada (1751), además de enumerar las superficies de terreno dedicadas a la agricultura, se menciona la existencia de dos hornos, uno de cal y otro de yeso, dependientes de la mayor hacienda agrícola de propiedad eclesial, que era la del Convento del Rosario de Madrid. La casa de labor y la administración se hallaban en la calle Real de Morata de Tajuña (5). El Catastro habla de que había dos panaderos (que ganaban 2.000 reales al año), dos molineros (2.200 al año), dos sastres (8 reales de jornal), un tejedor de lienzos (4 reales), un albéitar herrador con su aprendiz, que ganaban 8 y 3 reales diarios, respectivamente; dos herreros, padre e hijo, que trabajaban en su fragua con una ganancia de 9 reales diarios; dos zapateros y tres yeseros con una ganancia de 6 reales diarios.
En los Interrogatorios del Cardenal Lorenzana, de finales del XVIII se puede leer una interesante referencia a la iglesia del Santo Cristo de la Sala. El origen de este oratorio es el de haber sido un lugar de alojamiento ocasional de pobres transeúntes que dio lugar a una leyenda, estrechamente ligada con la producción de yeso: "En las afueras del pueblo había una antigua yesería que vagabundos, pobres y viajeros aprovechaban las edificaciones de ésta para protegerse del frío y para pasar la noche. En ella buscó refugio un vagabundo, antes de echarse a dormir dibujó un Cristo en la pared para rezar ante Él. Al día siguiente emprendió el camino; al llegar los trabajadores de la yesería encontraron la imagen que borraron. Al día siguiente los hombres quedaron perplejos al observar que el dibujo permanecía intacto en el mismo sitio. Por orden del jefe lo borraron de nuevo en presencia de él, ya que creía que no lo habían borrado el día anterior. Al tercer día de nuevo apareció el Cristo dibujado en la pared; corrió la voz por el pueblo y los vecinos acudieron a la yesería para comprobar con sus propios ojos el Cristo dibujado. Decidieron edificar una ermita en su honor. Las autoridades trataron de quitar importancia al asunto, pero fue tanta la presión del pueblo que al final accedieron en levantar una ermita en honor del Cristo aparecido" (5).

En el año 1734 se aprueban las Ordenanzas Municipales de la población. La villa se compone de 400 vecinos (unos 1.200 habitantes). Durante estos años se trabaja en nuevas canteras, yeseras y tejares para abastecer de materiales de construcción.

En 1827, Sebastián Miñano (6) no menciona la explotación de yesos, tal vez por su escasa importancia económica. Sin embargo, en 1848, Pascual Madoz (7) señala la existencia de "bastantes yeseras" al sur del municipio. A finales del siglo XIX, la industria de Morata de Tajuña es calificada como escasa por Diego Arribas (8). Para este autor, se compone en 1891 de buen número de ejemplos: una magnífica fábrica de papel continuo, dos molinos harineros, tres fábricas de yeso, una fábrica de teja, baldosa y ladrillo, otra de cerveza gaseosa, así como varios y buenos lagares para elaboración de vino.

Nosotros hemos constatado la existencia de yeserías de los siglos XIX y XX dentro del casco urbano y como es lógico en los terrenos sulfatados del Mioceno que aparecen al sur del pueblo, tras cruzar el río.

\section{EL FERROCARRIL DEL TAJUÑA}

Según puede leerse en la página web oficial del Ayuntamiento de Morata de Tajuña, el pueblo aprovechó la llegada del ferrocarril en 1901 para rentabilizar las posibilidades de sus canteras de piedra caliza, hornos de yeso 
y caleras que, durante todo el siglo $\mathrm{XX}$, monopolizaron la actividad industrial de la villa. A partir de 1925 la empresa Valderribas, S.A. explotó las canteras de caliza para sus hornos de cemento en Vicálvaro, mientras que otras empresas, como Lasical, S.A., también contaron con factorías para la elaboración de cal o de yeso.

Los periódicos de la época se mostraban expectantes ante los beneficios que el tren significaría para Morata. En la revista Blanco y Negro, que databa erróneamente la fecha de inauguración el 21 de julio y no el 25 del mismo mes, el periodista encargado de la información, tras relatar las dificultades del proyecto, señalaba que "así como el primitivo ferrocarril de Madrid a Arganda ha contribuido a la prosperidad de aquel suelo facilitando el transporte de vinos, cereales, piedra, yeso y cal, en que es abundantísimo, la línea inaugurada favorecerá la rica región del Tajuña".

En el Registro de la Propiedad del "Ferrocarril MadridArganda" (Tomo 1083), se puede leer: "El objeto que nos propusimos al solicitar la concesión del ferrocarril industrial desde Madrid a Vaciamadrid fue el de transportar a esta Corte los diversos materiales de construcción que se encuentran en la zona que atraviesa su trazo, a saber el pedernal que existe en Vicálvaro y que se emplea para el empedrado de las calles de esta capital y el yeso de Vaciamadrid que también se utiliza en las diversas construcciones de sus edificios. No hay en este trayecto ni la cal ni el guijo, ni las tierras para fabricar buen ladrillo del que tanto uso se hace en Madrid, a un precio excesivamente caro. Mas existiendo todos aquellos materiales en abundancia extraordinaria en el término de Arganda, de donde no pueden conducirse a Madrid por el elevado coste de los transportes, hemos querido que el desarrollo de las industrias respectivas en los parajes donde se encuentran sus materias primas sería de una utilidad incalculable para Madrid". La sociedad que se hace cargo de la explotación adopta el nombre de "Compañía del Ferrocarril Madrid-Arganda". La construcción y explotación queda dividida en dos secciones, la primera comprende el recorrido Madrid-Vaciamadrid, concedido en 1880, y la segunda, Vaciamadrid-Arganda, concedida en 1882. El 30 de julio de 1884, el Ministerio de Fomento en una Real Orden que publica La Gaceta autoriza la construcción de una vía férrea a los concesionarios de este ferrocarril "por un período de 99 años sin perjuicio de tercero" con arreglo a las leyes especiales de 6 de mayo de 1882 y a la de ferrocarriles de 23 de noviembre de 1877 .

El ferrocarril había surgido de la idea de prolongar la línea Madrid-Arganda hasta la población de Colmenar de Oreja, con posibilidad de construir un ramal entre Morata y Orusco. En 1890 se otorga licencia a Juan Carlos Morillo para la construcción de dicho ramal [...] No se conserva la estación de Morata, construida al norte del casco urbano ni el apeadero que existió junto a la fábrica de yeso del norte del término municipal (5).

Por Real Orden del Ministerio de Agricultura, Industria, Comercio y Obras Públicas de 19 de abril de 1901, se dispone la subasta para la adjudicación del ferrocarril Madrid-Vaciamadrid-Arganda, quedando el remate obligado para con el Estado en los mismos términos y con las mismas garantías que lo estaba la compañía originaria. Después de un largo expediente, se adjudica en subasta a D. Fernando López de Ribadeneyra, administrador delegado de la sociedad belga de ferrocarriles, que también adquiere la concesión de la línea de Arganda a Chinchón y Colmenar, así como el ramal de Morata de Tajuña a Orusco. Tras esta adquisición por la compañía belga, la economía del ferrocarril queda saneada, y se reanudan las obras que se habían iniciado en Morata, y cuando éstas están muy avanzadas, un desprendimiento de tierras sepulta a algunos de los obreros que trabajan en esta obra. El ferrocarril va extendiéndose por términos, de connotaciones mineras en muchos casos, tales como los argandeños de El Valle, Vahondo, El Alto y Cornicabra, y el 25 de julio de 1901, tras muchas vicisitudes, se inaugura el segundo tramo alcanzando la línea $44 \mathrm{~km}$. Este ferrocarril dará vida a las yeserías y caleras locales.

\section{YESOS DEL 50}

\subsection{Accesos}

La yesería está en un camino coincidente con la explanada de la antigua vía del tren de Arganda, ramal a Chinchón, Colmenar de Oreja, Villarubia de Santiago, etc., en su kilómetro 50, de donde toma el nombre. Para llegar hasta allí se parte del kilómetro 4 de la carretera de Morata a Perales de Tajuña por una pista de tierra que discurre hacia el sur, cruzando al otro lado del río por un puente metálico de remaches. Después, tras $2,5 \mathrm{~km}$ de recorrido, cruzando varías trincheras ferroviarias, se llega a la fábrica moderna, con su gran horno rotatorio, donde aún se conservan en pie 7 u 8 hornos antiguos, de los llamados morunos, convertidos en almacenes. Allí llegamos acompañados de D. Justo García Martín, un antiguo trabajador de la calera de Perales, de 65 años, ya jubilado.

\subsection{Historia}

D. Juan Zamorano, conocido como Juanito, de 70 años, yesero propietario de Yesos del 50 y su hijo de idéntico nombre cuentan cómo en la zona se empezó a producir yeso hace 187 años, cuando se instaló aquí la familia Moreno, de Perales de Tajuña. Tenían 30 o 40 borricos y 
vendían su producción en Perales, Tielmes, Villarejo de Salvanés y otros pueblos de la zona.

Pese a que la licencia para la construcción del ferrocarril de Madrid a Colmenar de Oreja, pasando por Arganda y Chinchón, data de 1890, la inauguración fue ya en el siglo XX (9). Con el tren se generó un apeadero en Yesos del 50 y la familia Zamorano pudo vender la mayor parte de la producción de yeso en Madrid (el ferrocarril entraba en la capital por la estación del Niño Jesús), el resto se llevaba con burros o algún carro a pueblos próximos. Una tía del padre de Juan Zamorano fue la que empezó con la empresa.

A principios de siglo XX los hornos fueron arrendados al Sr. Carreño, natural de Carabaña. Este empresario murió hace unos 60 años dejando a sus herederos un buen capital. Se supone que la Guerra Civil paralizó la yesería. El hecho es que en 1953 se dio licencia a la familia Zamorano para volver a la actividad productiva. El tren dejó de pasar por allí en 1968.

\subsection{Construcción de los hornos}

Los hornos se edificaron con piedra de yeso, labrada por la cara interior con piqueta de las que usan los albañiles. Estos mampuestos fueron unidos con yeso y barro. Las hiladas de piedra se iban cruzando para dar mayor consistencia al horno. Luego se rodearon los hornos con tierra, salvo por la zona de las bocas. Con esta operación pretendían evitar pérdidas caloríficas, por la poca conductividad del material envolvente, y conformar una rampa de carga de los hornos, por su parte superior.

La piedra de yeso para quemar se traía, desde la cantera, dentro de una vagoneta tirada por un caballo que subía por una vía, fatigosamente, siguiendo la rampa preparada al efecto. Una vez arriba se basculaba la piedra dentro del horno, desde su parte superior. El descenso de la vagoneta vacía era más sencillo, ya que lo hacía ella sola, aprovechando el desnivel.

Los mampuestos que forraban los hornos duraban mucho, porque la corriente de fuego tendía a propagarse hacia la parte central del horno. Por eso también las piedras de las orillas cocían peor y luego había que mezclarlas con las más interiores para obtener así un producto homogéneo.

Cuando se estropeaba un mampuesto del horno, se saneaba sustituyéndolo por otro, metiendo piedras nuevas, previa talla y considerando que cuanto más gruesas fueran, mejor. Esta operación se hacía sin utilizar andamiajes, el operario esperaba a que el horno se fuese rellenando hasta una altura que facilitase la reparación.

\subsection{Laboreo}

Extraían el yeso de canteras colindantes. La minería era manual, no estaba mecanizada. En los últimos tiempos de producción con los hornos morunos trabajaban en la explotación ocho operarios. Cuatro de ellos estaban con el martillo, distribuidos por parejas; en cada una de ellas uno picaba con el martillo neumático y el otro le ayudaba moviendo las gomas que iban hasta el compresor. El resto se dedicaba a barrenar y, sobre todo, también por parejas, a romper bloques con cuña y mazo (uno sujetaba la cuña o "pistolete" y otro arreaba con el mazo, pero nunca había accidentes). En los barrenos metían los "tacos", como llamaban a los cartuchos de explosivo empleados en las voladuras y que se adquirían en Vallecas. Iba el dueño en un taxi a por la munición y luego la dejaban en la puerta del cuartel de la Guardia Civil 3 o 4 horas hasta que venía el camión a recoger la carga.

\subsection{Hornos}

Los hornos eran 9 unidades colindantes, de cuba, cilíndricos y semienterrados en el suelo, que se conservan bastante bien, hoy convertidos en almacenes (Figura 1). Las paredes son de piedra de yeso, cortada casi como si fuera piedra de sillería. Las dimensiones de cada horno son 3,60 m de diámetro y $7 \mathrm{~m}$ de altura. Se accede a ellos por una puerta de $1,80 \mathrm{~m}$ de alto y $1,10 \mathrm{~m}$ de ancho, que atraviesa una pared de $1 \mathrm{~m}$ de espesor para evitar pérdidas caloríficas.

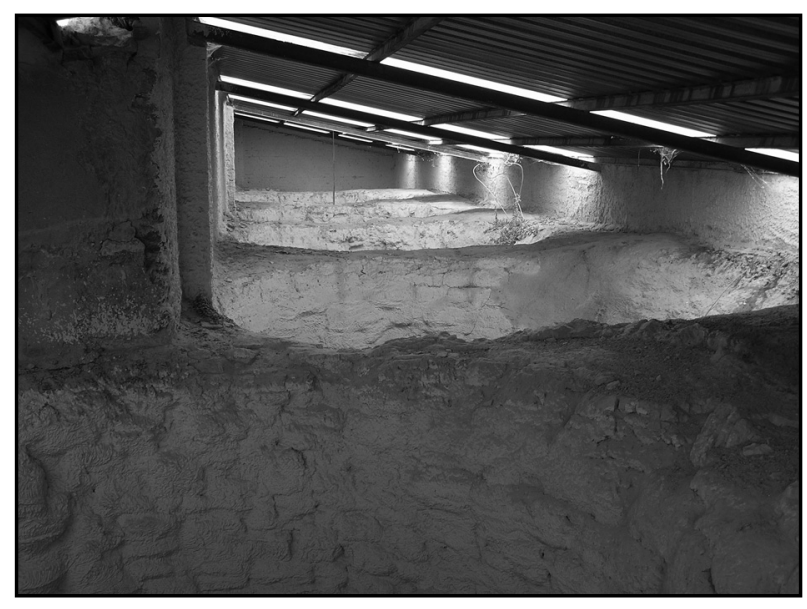

Figura 1. Los hornos morunos son ahora almacenes.

Hacían horno y medio diario, quemando por la noche. De esta manera conseguían evitar que las operaciones de introducción de la leña y de la molienda se entorpecieran una a otra. Cada horno producía $55,5 \mathrm{t}$, obteniéndose en la fábrica más de 73 t/día. Esta producción era empaquetada para su venta en sacos. Estos hornos eran, 
por tanto, de gran capacidad, para su época. En los hornos trabajaban por el día entre 11 y 12 hombres: siete traían la piedra desde la cantera, dos o tres levantaban la bóveda de piedra y otros dos cargaban piedra y casquijo. Por la noche trabajaban sólo dos, atizando el fuego y echando el cascajo (piedra menuda).

\subsection{Cocción}

Armar el horno llevaba un día. Primero se montaba una bóveda de piedra, operación que duraba algo más de dos horas y que culminaba cuando los operarios dejaban caer desde arriba la "cuña", piedra que cerraba la bovedilla por su parte superior. Luego, sobre esta resistente estructura, se echaba piedra fraccionada, desde arriba, para rellenar el hueco. Por encima del horno salía un copete ("montoncillo") cónico de casquijo que sobresalía 1,10 m del borde de la cuba. La cocción nocturna consumía de 800 a 900 gavillas de leña (encina, olivo, etc.) por cada horno. Estos haces eran de peso variable (15, 20, 25 o $30 \mathrm{~kg}$ ).

Cuando el yeso iba culminando la cocción, en la parte superior del horno aparecían rodales blanquecinos ("saltaban palomitas" en argot de yesero). Entonces el operario echaba por encima una, dos o tres espuertas de "tierra" (fragmentos finos de yeso, de deshecho) para impedir la salida de humos y forzar el tiro por otro lado. Tras realizar esta operación varias veces y ya cuando se ponía todo blanco, se dejaba de meter leña. Al culminar la combustión, el horno comenzaba a enfriarse. El aspecto del humo no lo consideraban como criterio para determinar la finalización del proceso, ya que pensaban que variaba con el tiempo atmosférico.

\subsection{Molienda}

La puertecilla que dejaban en la bóveda era mucho más pequeña que la de paso al interior del horno. Por ella se metían las gavillas de leña y entraba el aire necesario para la combustión. En su parte superior una barra de hierro sujetaba las piedras de la bóveda. Cuando finalizaba la cocción y el horno se había enfriado, éste se hundía quitando el dintel metálico de la puerta. La parte inferior del horno ("caldero") se cocía más, mientras que la parte superior ("cabeza") se quemaba peor. Por eso en la molienda había que ir mezclando materiales de ambas zonas, así como del centro y las paredes, para obtener un producto homogéneo. También había piedras mal cocidas, que al golpearlas con el martillo dejaban a la intemperie la parte interior sin deshacer ("hueso"). Estas piedras sin quemar se echaban de nuevo a otros hornos.

Antiguamente se molía con rulos de caliza del páramo (piedra de Colmenar) en una era. Luego se instaló un pequeño motor, el cual, mediante correas, transmitía el movimiento a una machacadora (trituración), así como a un molino receptor de los materiales de salida de la machacadora (refino). Esta máquina cuando se desmontó, se llevó a la calera de PREDESA en Morata de Tajuña, ubicada en la cuesta del carril de Arganda.

El material molido se envasaba en sacos de yute, y también de esparto o arpillera. Los sacos de esparto eran malos para los trabajadores, ya que al llenarlos, por el contacto directo con el yeso, se les quemaban y agrietaban las manos. La unidad de medida productiva era el cahíz (690 kg), que equivalía a 14 sacos de casi unos 50 $\mathrm{kg}$ cada uno.

Sólo se producía yeso y no escayola. Este dato queda corroborado por los índices de pureza, medidos en el LOEMCO, con valores comprendidos entre 80 y 85 .

\section{OTRAS YESERÍAS DEL MUNICIPIO DE MORATA DE TAJUÑA}

\subsection{Datos generales}

En Morata ha habido algunas yeserías más. Una de las más conocidas, la de D. Manuel García, producía unas escasas 100 t anuales (10). La de D. Fermín Fernández se ubicaba en la calle Mac-Crohon, esquina con la calle Iglesia. Ya no existe al haberse construido viviendas en el lugar que ocupaba. Respecto a otras fábricas de yeso, cabe señalar que sus restos se ubican junto a la carretera de Valdelaguna, tras cruzar el río, hacia el $\mathrm{km} \mathrm{2,} \mathrm{y} \mathrm{al}$ llegar a los primeros escarpes montañosos. Se trata de la cantera de "Los Postulas" (Víctor, Julián y José Sánchez González), que repartían yeso por Morata con una mula, y cuyo horno ya desapareció; según Martínez Lominchar, funcionaba ya en el siglo XIX (9). Junto a ella se levanta la yesería de D. Eugenio Fernández, con restos de 6 hornos (Figura 2).

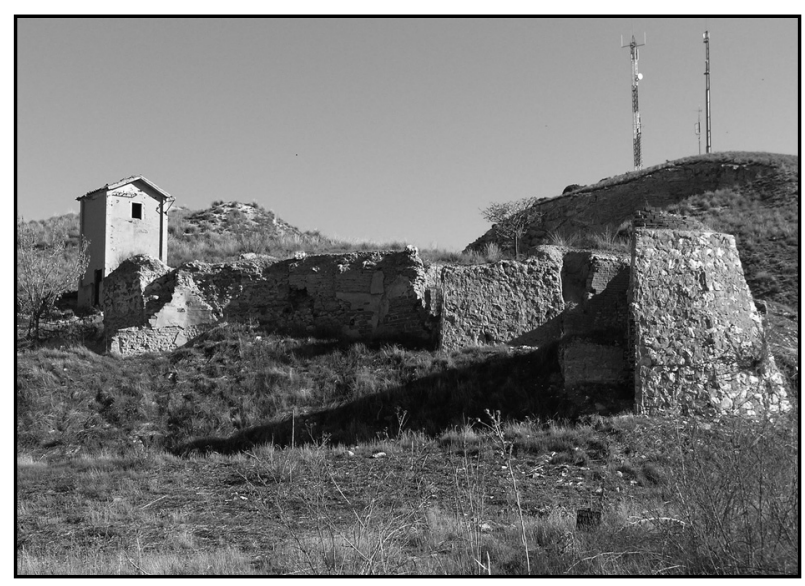

Figura 2. Vista general de las instalaciones YECESA. 
La familia de D. Eugenio Fernández tuvo también dos hornos "árabes", junto al matadero, hoy ya desaparecidos. D. Eugenio, de 65 años, nos cuenta que los hornos de la carretera de Valdelaguna se levantaron cuando él tenía 7 u 8 años, a finales de los años 40, y funcionaron hasta principios de los 70 . Creemos que la empresa se llamaba YECESA.

\section{YECESA}

Los cinco hornos más próximos a la carretera son de cuba, cilíndricos, colindantes y están excavados en el suelo para evitar pérdidas caloríficas. De uno casi no quedan restos, otros cuatro están en bastante mal estado. Están revestidos de ladrillos normales, y en algún caso de ladrillos refractarios, y muestran doble camisa (Figura 3) con espesor total de muro de 0,90 m. Su diámetro es $3,25 \mathrm{~m}$ y su altura, 4,5 m. Un muro de mampuestos de caliza del páramo refuerza por el exterior la estabilidad del conjunto. Los accesos a uno de los hornos se han conservado como almacén. En otros casos son portalones más sencillos.

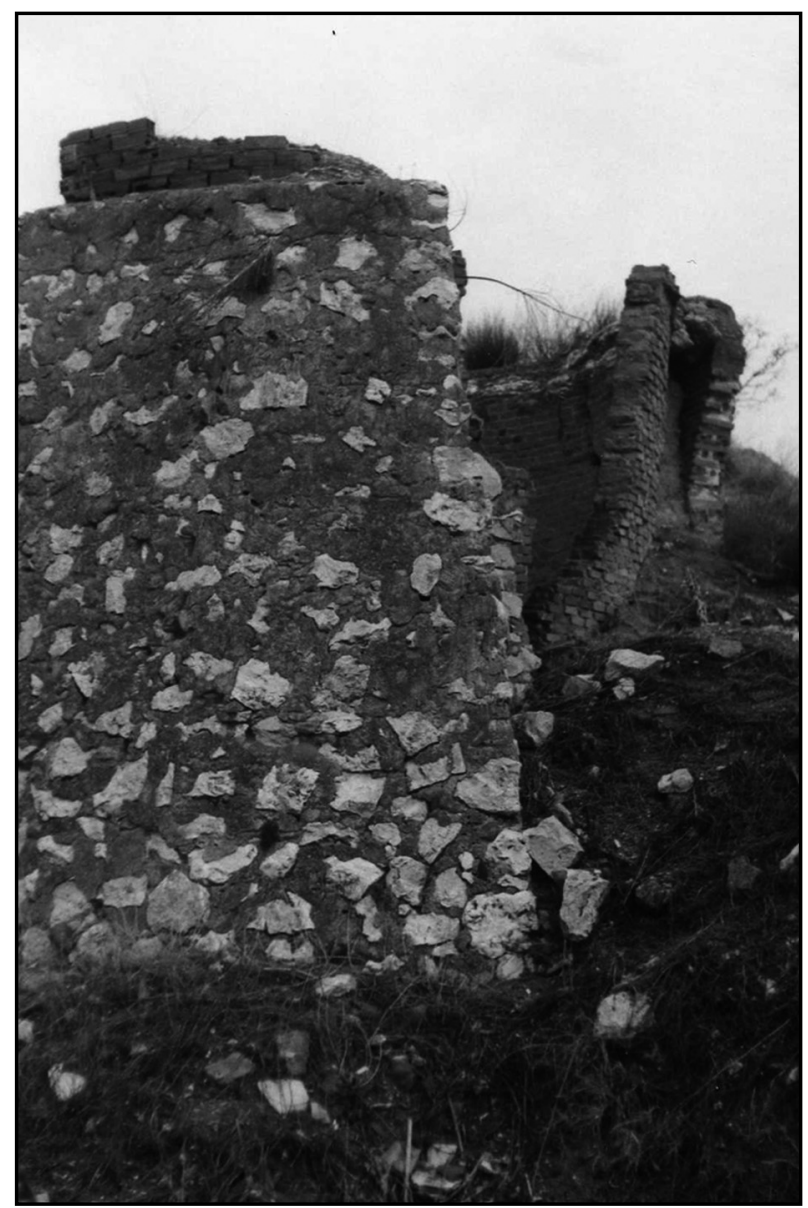

Figura 3. Vista externa de un horno.
Por encima de estos hornos aparecen restos de mampuestos calizos diseminados por los alrededores. El solado y parte de un muro nos indican la posición de una antigua casa, tal vez las oficinas de la empresa. Asimismo, se alza el edificio, sin que quede ya la puerta de un transformador. Es una esbelta construcción de ladrillo hueco, cubierto por un revoco, y tejado de teja árabe (Figura 4).

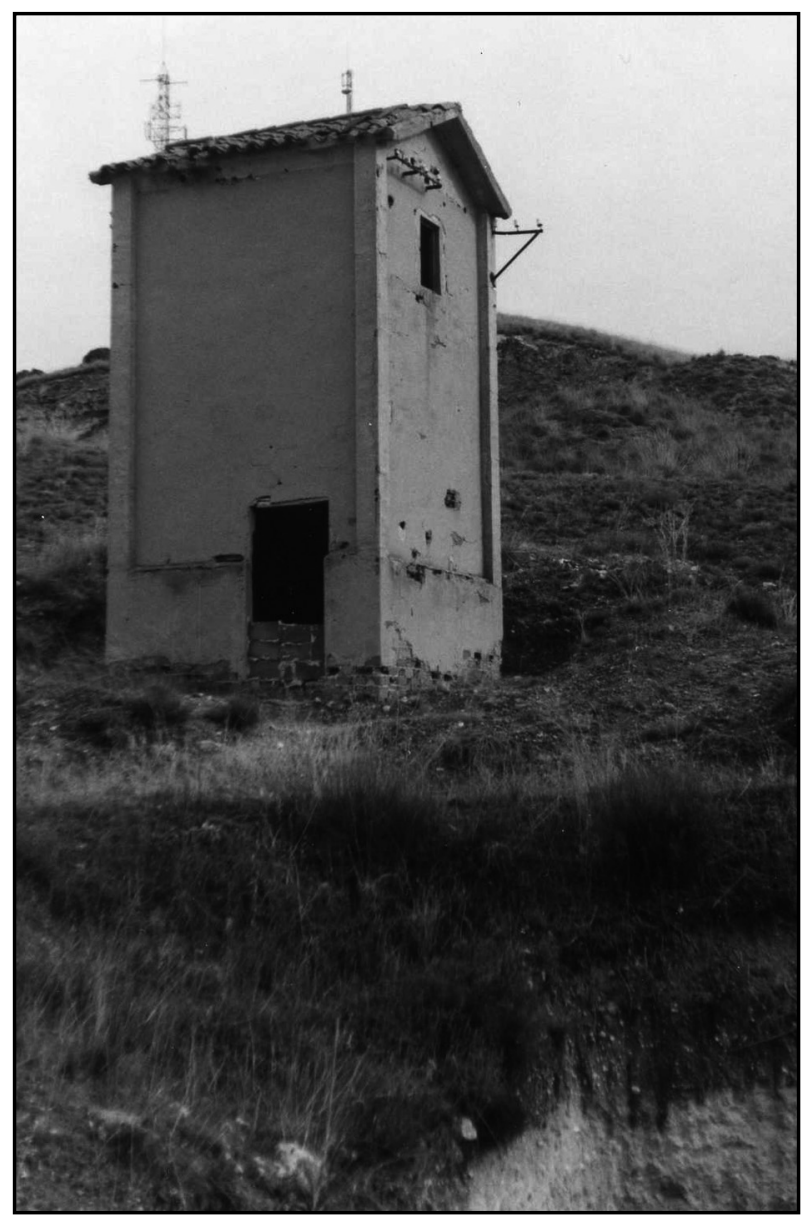

Figura 4. Vista del transformador.

En el interior de la cantera quedan restos de otro horno más achatado, de mejor porte, y con una rampa de carga, forrada de mampuestos calizos, desde el suelo hasta la parte superior. Las dimensiones del horno son 4,2 $\mathrm{m}$ de diámetro y 2,5 $\mathrm{m}$ de altura desde la parte superior hasta el punto donde se colocó una parrilla para sujetar la carga y recibir fuego desde abajo. La camisa es triple: muro de ladrillo macizo, otro muro de ladrillo colindante, relleno de tierra y yeso, así como, de nuevo, muro de ladrillo por la parte externa, siendo el espesor del paquete de $0,90 \mathrm{~m}$. La parte de la embocadura ha quedado destruida (Figura 5). Desde este horno partía un camino semiempedrado hacia la carretera próxima. 


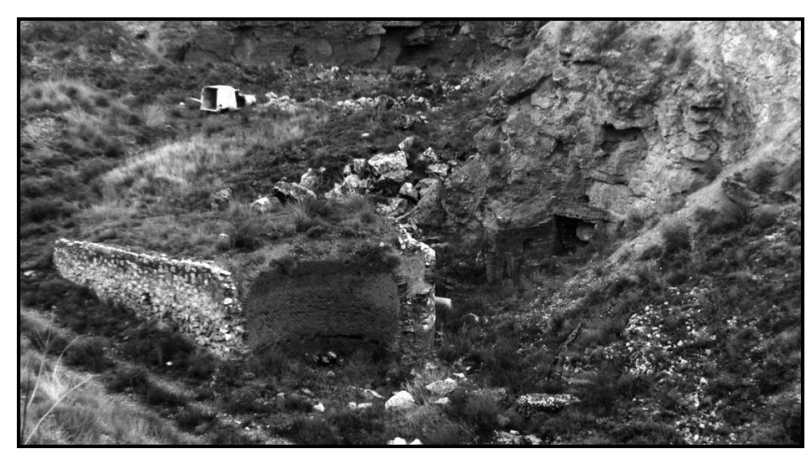

Figura 5. Restos de un horno en interior de cantera.

En los hornos sólo se fabricaba yeso. La calidad de la piedra no era óptima para producción escayola. D. Eugenio nos contó que levantar un horno llevaba un día y quemarlo, 24 horas. Empleaban como combustible leña (encina), ramón de oliva, cañas y lo que hubiese. En la molienda no cabe duda que intervenía la energía eléctrica. Una vez finalizado el proceso productivo, vendían el yeso a los albañiles, transportándolo en carros tirados por mulas. Todavía quedan restos de las estructuras troglodíticas donde guardaban las herramientas.

\section{CONCLUSIONES}

Sería conveniente proponer alguna iniciativa para conservar el patrimonio material e inmaterial yesero en la zona, de tan rica tradición artesanal.

Proponemos la acogida de los hornos antiguos en el Catálogo Municipal de Bienes Inmuebles Protegidos, por su interés cultural.

Proponemos también intervenciones de conservación y restauración de estos elementos industriales, así como la creación de un Centro de Interpretación o un Museo del Yeso y de la Cal (y tal vez del cemento).

\section{AGRADECIMIENTOS}

A D. Juan Zamorano (padre, y a su hijo, del mismo nombre) y a D. Eugenio Fernández, todos ellos yeseros, por sus explicaciones. Así como a D. Justo García, antiguo calero, por acompañarnos en los recorridos de campo y por aportarnos algunos datos.

\section{BIBLIOGRAFÍA}

(1) Puche, O., Mazadiego, L. F. y Orche, E.: "Hornos morunos de yeso en la Comunidad de Madrid", Actas del Simposio sobre Patrimonio Geológico y Minero. IV Sesión Científica de la Sociedad Española para la Defensa del Patrimonio Geológico y Minero (Belmez, 28-30 de octubre de 1999). Ed. SEDPGYM., T. II., 1998, pp. 50-67.

(2) Martín Bourgón, P., Campos Juliá, C. y San José Lancha, M. A.: Memoria del Mapa Geológico de España, a escala 1:50.000, Hoja 573: Arganda. 2a serie. Ed. Instituto Geológico y Minero de España, Madrid, 1975.

(3) Alvar Ezquerra, A.: Relaciones topográficas de Felipe II. Madrid. Transcripción de documentos. Ed. CAM-CSIC. V. I, Madrid, 1993, pp. 483-495.

(4) Sánchez Meco, G.: El Escorial y la orden Jerónima: análisis económico-social de una comunidad religiosa. Ed. Patrimonio Nacional, Cfr. Madrid, 1985, pp. 87-89.

(5) Torre Briceño, J. A. de la: Historia de la villa de Morata de Tajuña. Ed. Ayuntamiento de Morata de Tajuña, Madrid, 1999, pp. 101 y $179-180$.

(6) Miñano, S.: Diccionario geográfico-estadístico de España y Portugal. Imprenta Pierrart-Peralta. T. VI, Madrid, 1826, p. 138.

(7) Madoz, P.: Diccionario geográfico-estadístico-histórico de España y sus posesiones de ultramar. Ed. L. Sagasti y P. Madoz. T. XI, Madrid, 1848, pp. 588-589.

(8) Diego Arribas, J. de: Morata de Tajuña. Biblioteca de la Revista Ilustrada La Provincia, Madrid, 1891, pp. 35-41.

(9) Martínez Lominchar, R.: Rutas del Tajuña: entornos de Colmenar de Oreja, Chinchón, Morata de Tajuña, Titulcia y Villaconejos. Los Libros de la Catarata, Madrid, 1996, p. 9.

(10) Castells, J. y Concha, S. de la: Memoria del Mapa Geológico de España, a escala 1:50.000, Hoja no 573: Arganda. Ed. Instituto Geológico y Minero de España, Madrid, 1951. 